\title{
On the Relationship between Organizational Trust and Change and the Mediating Role of the Commitment to Change in Sanandaj Insurance Companies
}

\author{
Heidar Golisyvanani \\ M.A. in Insurance Management, Department of Management, Islamic Azad University \\ Sanandaj Branch, Sanandaj, Iran \\ Parastoo Sedaghat
}

Assistant Professor, Department of Management, University of Kurdistan, Sanandaj, Iran Email: parastoo.sedaqat@gmail.com (Corresponding Author)

\section{Doi:10.5901/mjss.2015.v6n6s6p252}

\section{Abstract}

This study examined the relationship between organizational trust and change and the mediating role of the commitment to change in Sanandaj insurance companies. The population of this study $(N=159)$ includes the employees of Sanandaj insurance companies. Using classified random sampling with proportional allocation to the population size of each company, 112 insurance companies' employees and managers were selected as samples of this study. Questionnaires were used to collect data. The data was analyzed by statistical software in both descriptive and inferential levels, using structural equation modeling. The questionnaires' reliabilities were calculated by Cronbach's alpha coefficient. The reliabilities of organizational trust, organizational change, and commitment to change questionnaires were $.857, .786$, and .761, respective. All assumptions were confirmed at the $95 \%$ confidence level and the results revealed that organizational trust has had a significant effect on the organizational change. With regard to the extent of impact on the organizational change, the horizontal aspect of the trust ranked first. Vertical aspect of the trust and institutional trust ranked second and third, respectively.

Keywords: Organizational trust, organizational change, commitment to change, insurance companies, Sanandaj city.

\section{Introduction}

Today, all aspects of human life including science and technology are quickly experiencing changes. In order to survive and be dynamic, organizations are forced to have constant changes and innovations. The world is constantly changing and according to Drucker, the only constant issue is change in today's world. If there was no need for change, evolution, and innovation, human had still remained in the early human life of and perhaps at the level of animal life and no changes would occur in his knowledge, attitudes and behavior. If human beings do not have the variability and reforming features, they had remained within their narrow thinking framework and their progress was blocked. As a result, in today's competitive world, the need for rapid organizational change and managing it is one of the basic conditions for the success of the organizations.

In a turbulent global market and within the territory of the organization, one of the means to adjust the organizations based on complex operations is organizational structure process some of which include cooperation with consultants out of the organization. In most of the cases, due to their multiple agencies, these consultants have an extensive and deeper perspective on the complexity of environmental factors with regard to some organizational, political, and individual factors; however, it is not an easy job to work with external consultants. It is in the case that the organizations are striving to deal with the gradual development of economical, technological, and social chaos of the environmental factors and make their employees accommodate such changes (Stanley et al, 2005, pp. 429-459) Therefore, any factor that can help to organizational change is important.

Today in the organization, there is not a huge organizational change processes (Kotter, 1996). (Pettigrew, 1990, pp. 270-290) Pettigrew defines the organizational change as a result of changes in both the content and the process. One of the most important elements in the process of change is assessing the results of the works done. It means that successful organizational change is dependent on various factors, including external and internal factors, process oriented factors such as speed and quality (Pettigrew et al, 2001,700-713), and results-oriented factors such as business results and organizational performance improvement (Szamosi and Duxbury, 2002). When an innovation is to change the 
organization, regardless of the industry sector, the organization tends to employ consultants in order to help them successfully implement organizational processes (Appelbaum and Steed, 2005, pp. 70-90). Because factors such as speed and quality may be found to successfully change the organizational process. Another factor is the social relations, i.e a positive bilateral relationship between customers and factors of external changes, such as consultants. Consultation is important in the process of change and it is not surprising that organizational events (i.e. the change process) are a starting point for the emotional reaction (Weiss and Cropanzano, 1996, pp. 1-74). In this case, the relationship between consultants and customers has a personal perspective which is not established on the basis of trust among others (Appelbaum and Steed, 2005, pp. 70-90). The role of trust in common relations between firms is one of the basic principles. (Zaheer et al, 1998, pp. 145-150) It may be part of a comprehensive perspective of bilateral relations between people and organizations. This shows that in order for organizational change initiatives to be successful, both micro (individual) and macro (organizational) factors should be combined.

The aim of this study is to examine the relationship between organizational trust and organizational change and the mediating role of commitment to change in Sanandaj insurance companies.

Organizational Trust: It refers to expecting positive results of one party based on the expected action from the other side in an interaction characterized by uncertainty.

Commitment to change: Many researchers have emphasized that commitment to change is an essential component in the efforts for organizational change. Thus, according to Klein, et al. (1996), commitment to change is central to the implementation of innovation in organizations (klein et al, 1996, pp. 1055-1080). Therefore, based on the model of commitment to the workplace, they have defined commitment to change as a mental force and psychological state which make people commit to actions that are necessary for the successful implementation of change measures.

Haras, Kowich, and Meyer presented 16 indices in order to measure employees' commitment to implement the change. The employees' acceptance and support is very important for the success of the organizational change. The organization's understanding of the employees' reaction and their approach to organizational change is important in the change process (Piderit, 2000, pp. 785-790). One of the concepts used to explain a variety of these reactions and approaches is commitment to change.

Organizational change: Robert (1964) defines change according to Webster's dictionary as follows: Change means picking up or putting things in another place. Change also means the same in organizations so the organization activities in the current situation become a different situation. Frederick Nichols defines change as: One thing that is transferred from one place to another. Transfer from a problematic position to a problem-solving position. According to March (1981), the concept of organizational change refers to a set of solutions from different groups within an organization.

In this study, it is assumed that there is a significant relationship between organizational trust and organizational change. Sub-assumptions are: 1 . There is a significant relationship between the institutional trust and organizational change. 2. There is a significant relationship between horizontal trust and organizational change. 3 . There is a significant relationship between vertical trust and organizational change. 4. Commitment to change has a significant impact on the relationship between organizational trust and organizational change.

\section{Review of the Literature}

Salvati and Salasi (2014) carried out a study entitled "The relationship between (change strategies) and (commitment to implement the change)" to investigate the relationship between change strategies and commitment to implement the changes in BoroujerdSaderat and Tejarat Banks. Design / methodology/approach: Samples consisted of 173 the banks' employees. They were selected based on stratified random sampling proportional to population size. Regarding the methodology, the study is a descriptive correlational one. To measure the basic concepts of research, a questionnaire was designed. Research data were analyzed using statistical tests. Findings: The results showed a significant correlation between change strategies and its dimensions and commitment to implement the change in these bank branches. Considering organizational change strategies, collaborative strategies brought about the greatest commitment to implement the changes. It can be introduced as "a strong commitment to implement the changes". On the other hand, verbal strategies, among other change strategies, had the least amount of commitment to implement the change. It also can be introduced as "weak commitment to implement the changes".

YarMohammadian et al. (2012) conducted a study under the title of "The relationship between organizational justice, job satisfaction, organizational trust, and organizational commitment and the self-assessment of organizational excellence to provide a predictive model (case study of professors in Islamic Azad universities of four parts of the countries). The results showed that the variables playing a ley role in explaining the self-assessment of business excellence include: distributive justice, trust to organization, and trust to colleagues. The distributive justice has a direct 
impact (.491) and an indirect impact (.137) mediated by organizational commitment on the self-assessment of the organization excellence. The trust to colleague has a direct effect (.319) and an indirect effect (.089) mediated by organizational commitment. Other variables in model have a weaker direct or indirect impact on the self-assessment of organizational excellence. According to the tested fitness parameters of the model, the final research model is fitting relatively well.

Moghadam (2011) done a research entitled "The role of mental models in the process of organizational change (case study of one of the companies producing tissue paper in Iran". The results of this study showed that the research has investigated the role of managers' mental models in the process of organizational change.

Singh and Shour (2009) studied the relationship between interpersonal trust and organizational citizenship behavior and found that the frequency of interactions among individuals, stability, and competence are important predictors of interpersonal trust and interpersonal trust has a positive relationship with organizational citizenship behavior.

In an attempt to unify the conflicting literature on the effects of trust on the organizations, Mc Evily, Perrone, \&Zaheer (2003) conceptualized trust as a principle of regulation through which organizations regulate and coordinate their activities. They argue that trust, forming patterns of interaction between the mediators, affects the regulation and stimulates these actors to support and combine the resources.

Dirks, et al. (2001), the literature on the role of trust in organizational environments shows that trust has directly or compensatory effects on a variety of favorable performances and variables of behavioral outcome. In their review, trust facilitates the effects of other determiners on the performance or behavioral outcomes because trust provided the conditions under which specific outcomes are more likely to occur.

Conceptual model of this study is derived from the model of the studies obtained from Ben-Gal and Tzafrir (2011) and scientific discussions on this subject. This model demonstrates how trust and organizational change mediated by commitment to the change affects.

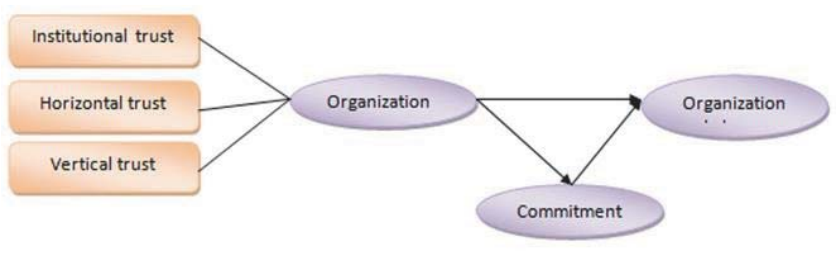

Figure 1. Conceptual model of the study

Conceptual model of the study (Ben-Gal and Tzafrir, 2011)

\section{Methodology}

According to the research objectives, it is regarded as applied research. To classify research based on the purpose, it is applied. In terms of method, it is the descriptive and correlational. This descriptive study is to describe the situation of society. This correlational study is to predict and analyze the relationship between the variables. According to the data collection time, it is a cross-sectional study. Questionnaires will be used in this study. In fact, this research seeks to collect data to describe the current situation in order to answer the questions and test research hypotheses. The main question of this research is as follows: What is the relationship between organizational trust and organizational change mediated by commitment to change?

In the analytical model, the organizational trust is the independent variable, organizational change is dependent variable and commitment to change is mediating variable. The main means of data collection is a questionnaire which contains 43 questions on organizational trust (each dimension respectively, 14 questions on horizontal trust, 14 questions on vertical trust and 15 questions on institutional trust), 10 questions on the organizational change and 18 questions on the commitment to change, with a 5-point Likert scale. In order to assess the reliability, the first draft contained 30 pre-test questionnaires. Using the data obtained from the questionnaire, reliability coefficient was calculated by Cronbach's alpha. Considering variables, the reliability was $.857 \%$ for organizational trust (.756 for horizontal trust, .739 for vertical trust, and .764 for institutional trust), .786 \% for organizational change and .761\% for commitment to change. These indicate that the questionnaire is reliable and valid. The population of this study $(n=159)$ include the employees of Sanandaj insurance companies. The sampling method used was simple random sampling. 112 employees were selected as statistical sample size based on the Cochran formula. 


\section{Results}

Descriptive statistics of the research demographic variables are presented in Table 1:

Table 1. Descriptive statistics of the research demographic variables

\begin{tabular}{|c|c|c|}
\hline Percent of frequency & Levels & Demographic Variable Name \\
\hline 33 & female & \multirow{2}{*}{ Gender } \\
\hline 67 & male & \\
\hline 17 & Diploma & \multirow{4}{*}{ Education } \\
\hline 17 & AA & \\
\hline $62 / 5$ & $\mathrm{BA}$ & \\
\hline $3 / 5$ & MA & \\
\hline $10 / 7$ & Under25Years old & \multirow{5}{*}{ Age } \\
\hline $25 / 9$ & $35-25$ Years old & \\
\hline $25 / 9$ & 45-36Years old & \\
\hline $19 / 6$ & 55-46Years old & \\
\hline $17 / 9$ & 55overYears old & \\
\hline $30 / 4$ & Under 5 Years old & \multirow{4}{*}{ Work Experience } \\
\hline $37 / 5$ & 10-6Years old & \\
\hline $9 / 8$ & 15-11Years old & \\
\hline $22 / 3$ & 20-16Years old & \\
\hline
\end{tabular}

Table 2. Mean test of a population $\left(H_{0}: \mu=3\right)$

\begin{tabular}{|c|c|c|c|c|c|c|c|}
\hline Variable status & maximum & minimum & Sig. & T statistics & SD & Mean & Variable \\
\hline suitable & $0 / 272$ & $0 / 043$ & $0 / 007$ & $2 / 724$ & $0 / 611$ & $3 / 157$ & Organizational Trust \\
\hline suitable & $0 / 378$ & $0 / 125$ & $0 / 000$ & $3 / 927$ & $0 / 677$ & $3 / 251$ & Horizontal trust \\
\hline suitable & $0 / 295$ & $0 / 011$ & $0 / 035$ & $2 / 131$ & $0 / 76$ & $3 / 153$ & Vertical trust \\
\hline medium & $0 / 171$ & $-0 / 025$ & $0 / 14$ & $1 / 485$ & $0 / 522$ & $3 / 073$ & Institutional trust \\
\hline
\end{tabular}

Table 3. Mean Test of a population $\left(H_{0}: \mu=3\right.$ )

\begin{tabular}{|c|c|c|c|c|c|c|c|}
\hline Variable status & maximum & minimum & Sig. & T statistics & SD & mean & Variable \\
\hline suitable & $0 / 562$ & $0 / 311$ & $0 / 000$ & $6 / 879$ & $0 / 672$ & $3 / 437$ & Organizational change \\
\hline
\end{tabular}

Table 4. Mean Test of a population $\left(H_{0}: \mu=3\right)$

\begin{tabular}{|c|c|c|c|c|c|c|c|}
\hline Variable status & maximum & minimum & Sig. & T statistics & SD & mean & Variable \\
\hline suitable & $0 / 376$ & $0 / 124$ & $0 / 000$ & $3 / 919$ & $0 / 675$ & $3 / 25$ & Commitment to change \\
\hline
\end{tabular}

\section{Analyzing the Structural Model of the Study (Path Analysis)}

To test the hypotheses, structural equation modeling was used. It is a general and powerful multivariate analysis technique from multiple regression class and lets the researcher simultaneously examine a set of regression equations. LISREL or Structure Equation Modeling (SEM) is a very general analytical technique from the multivariate regression class. In other words, it is an extension of "the General linear model" which let researchers simultaneously examine a set of regression equations. Structural equation modeling is a comprehensive approach to test the hypotheses on the relationship of the observed and latent variables and it is sometimes called covariance structure analysis, causal modeling and LISREL; however, structural equation modeling or SEM is the most common one these days (Hooman $1384,11)$.

According to Azar (2001), multivariate analysis is one of the most powerful and the most suitable analysis in behavioral and social sciences research because these subjects involve several variables and cannot be solved by bivariable techniques(in which one independent variable and a dependent variable are considered each time). "Analysis of 
covariance structures" or "structural equation modeling" is one of the main methods for the analysis of complex data structures and one new method to evaluate causal relationships. It is a meaningful analysis of several variables in a theory-based structure and suggests the effects of variables on each other at the same time. Using this method, the acceptability of theoretical models in particular societies can be tested by correlational, non-pilot, and pilot data.To assess the factors affecting organizational change and to determine the coefficients of each of the variables affecting it, structural equation modeling with LISREL software is used. As mentioned, LISREL or structural equation modeling is a very general and powerful multivariate analysis technique from the multiple regression class it is an extension of "the General linear model" which let researchers simultaneously examine a set of regression equations. Analysis of covariance structures or structural equation modeling is one of the main structural analysis techniques for complex data and it, as a new technique, examines the causal relationships. It is a meaningful analysis of several variables in a theory-based structure and suggests the effects of variables on each other at the same time. Using this method, the acceptability of conceptual models which are multivariate subjects can be solved and they cannot be solved by bivariate techniques (in which one independent variable and a dependent variable are considered each time). In other words, the structural modeling exclusively explains the causal relationships between latent variables. The purpose of this model is to discover direct and indirect effects of the extrinsic latent variables on intrinsic latent variables.

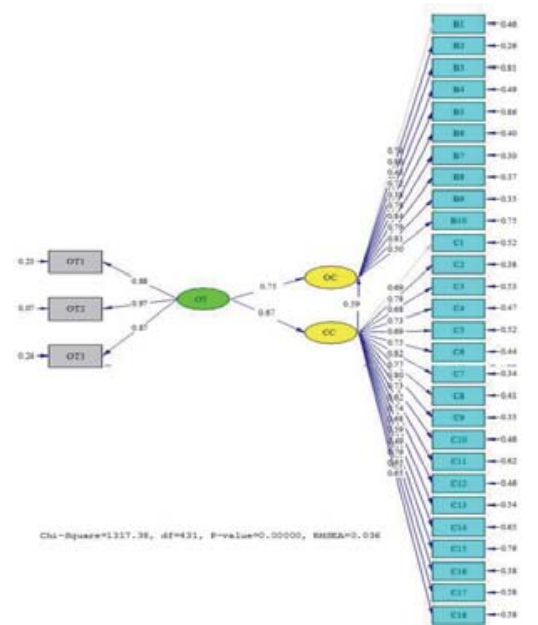

Figure 2: Structural modeling of the study estimating the standard (the main research hypothesis)

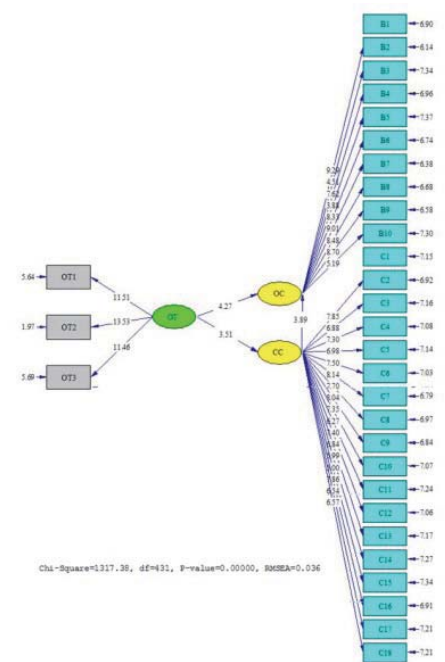

Figure 3: The structural modeling of the research with a significant number (the main research hypothesis) 


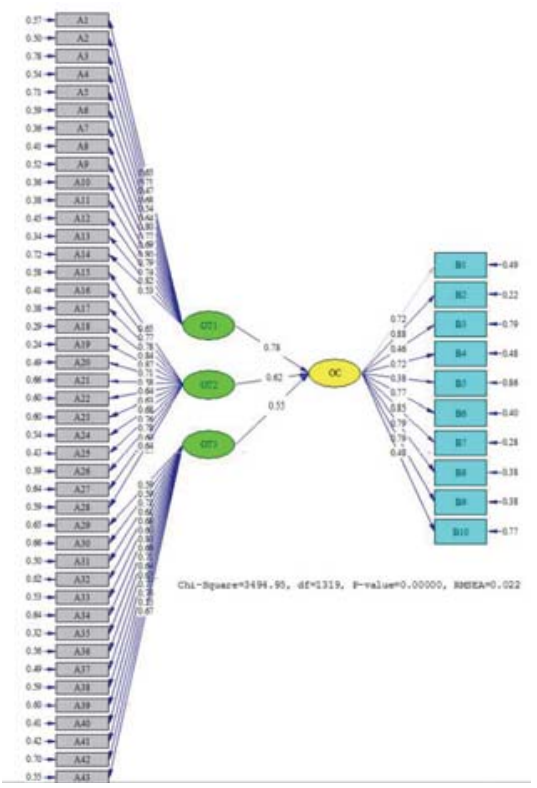

Figure 4: Structural modeling of the study estimating the standard (sub-hypotheses)

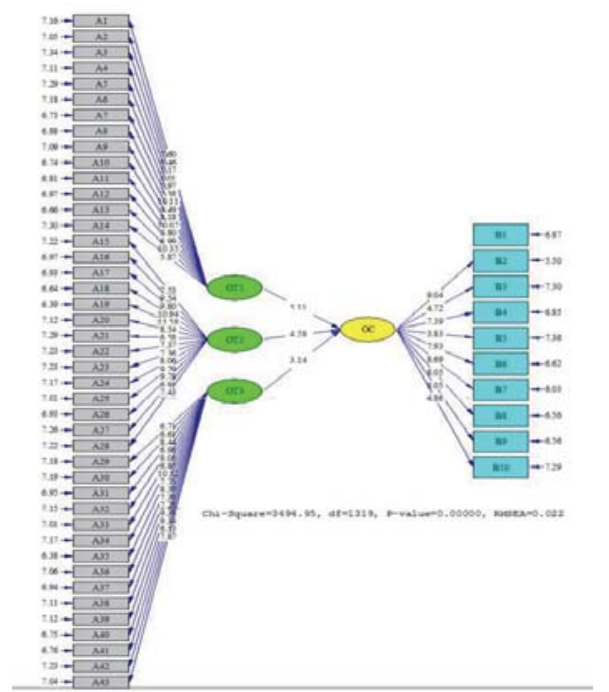

Figure 5: The structural modeling of research with a significant number (sub-hypotheses)

Table 5. Results of testing the hypotheses related to research hypotheses

\begin{tabular}{|c|c|c|c|c|c|c|}
\hline Rank & Results & $T$ & Path coefficient & Path direction & \multicolumn{2}{|c|}{ Research hypotheses } \\
\hline- & Approved & $4 / 27$ & $0 / 75$ & Between the organizational trust and organizational change & \multicolumn{2}{|c|}{ main hypothesis } \\
\hline 1 & Approved & $5 / 11$ & $0 / 78$ & between horizontal trust and organizational change & $H_{1}$ & $\mathscr{O}$ \\
\hline 2 & Approved & $4 / 58$ & $0 / 62$ & between vertical trust and organizational change & $\mathrm{H}_{2}$ & 崖 \\
\hline 3 & Approved & $3 / 14$ & $0 / 55$ & between institutional trust and organizational change & $\mathrm{H}_{3}$ & 올 \\
\hline - & Approved & - & $0.67 \times 0.59=0.40$ & $\begin{array}{l}\text { commitment to change on the relationship between trust and } \\
\text { organizational change }\end{array}$ & $\mathrm{H}_{4}$ & $\begin{array}{l}\text { 皇 } \\
\text { ल }\end{array}$ \\
\hline
\end{tabular}


All research hypotheses (the main hypothesis and 4 sub-hypotheses) are accepted because $T$ path coefficients for all variables are more than 1.96, so all assumptions are approved. It can be seen that organizational trust (coefficient .75 and sig. 4.27) have significant relationship with organizational change. Regarding the dimensions and their impacts on the organizational change, horizontal trust (coefficient .78 and sig. 5.11) is in the first place and the vertical trust (coefficient .62 and sig. 4.58) and institutional trust (coefficient .55 and sig. 3.14) ranked next, respectively. Commitment to change has an effect on the relationship between organizational trust and organizational change and has reduced the amount of impact to some extent and the amount of effect is reduced from .75 to .40 .

\section{Goodness of Fit Tests}

Although various types of tests called fitness indices are steadily being compared, developed, and completed, there is no consensus on one optimal test yet. The result is that different articles, such as SEM have provided various indices limitations and famous authors even run large number of fitness test using Amos and EQS Lisrel software. After determining the model, there are several ways to estimate the goodness of fit of the model sing the observed data. Generally, several indices are used to measure the model goodness of fit; however, using three to five indices is sufficient to support the model. Overall, the following indices are used to evaluate the goodness of fit of the general model. The number related to $\mathrm{CFI}, \mathrm{NNFI}, \mathrm{NFI}, \mathrm{RMSEA}, \mathrm{AGFI}, \mathrm{GFI}, \mathrm{RMR}$ indices are presented in Table (7).

Table 6. Goodness of fit indices of the model

\begin{tabular}{|c|c|c|c|c|c|}
\hline Result & Values for our model & Valid values for optimal fit model & Range & Type of index & Index \\
\hline Accepted fitness of the model & $\begin{array}{c}\text { Chi-square=1317/38 } \\
\mathrm{P}=0 / 38\end{array}$ & $\begin{array}{c}\text { Significance level P is greater } \\
\text { than .05. }\end{array}$ & --- & Chi-Square \\
\hline $\begin{array}{c}\text { than the amount of the } \\
\text { independent model= 421.51 } \\
\text { So, accepted }\end{array}$ & $124 / 32$ & $\begin{array}{c}\text { Less than the amount of the } \\
\text { independent model }\end{array}$ & No range & $\begin{array}{c}\text { Information } \\
\text { criterion }\end{array}$ & $\begin{array}{c}\text { Akaike } \\
\text { Information } \\
\text { Creterion }\end{array}$ \\
\hline $\begin{array}{c}\text { than the amount of the } \\
\text { independent model=607.50 } \\
\text { So, accepted }\end{array}$ & $284 / 11$ & $\begin{array}{c}\text { Less than the amount of the } \\
\text { independent model }\end{array}$ & No range & $\begin{array}{c}\text { Information } \\
\text { criterion }\end{array}$ & CAIC \\
\hline accepted & $\begin{array}{c}\text { Standardized RMR } \\
0 / 026\end{array}$ & less than .9 & 0 and 1 & $\begin{array}{c}\text { Information } \\
\text { criterion }\end{array}$ & $\begin{array}{c}\text { RMR }{ }^{1} \\
\text { standard }\end{array}$ \\
\hline accepted & $0 / 91$ & Greater than .9 & Between 0 and 1 & Comparative & $\mathrm{GFI}^{2}$ \\
\hline accepted & $0 / 92$ & Greater than .9 & Between 0 and 1 & Comparative & TLIor $^{3} \mathrm{NNFI}$ \\
\hline accepted & $0 / 91$ & Greater than .9 & Between 0 and 1 & Comparative & $\mathrm{CFI}^{4}$ \\
\hline $\begin{array}{c}\text { The sample size was 112 and } \\
\text { bigger accepted }\end{array}$ & 57 & For different models & No range & $\begin{array}{c}\text { Sufficiency of } \\
\text { sample size }\end{array}$ & Ncritical \\
\hline
\end{tabular}

\section{Conclusion}

All research hypotheses were confirmed in this study. Results showed that institutional trust with the coefficient (.736) has a significant impact on the organizational change. Regarding the sub- hypotheses, horizontal trust (second hypotheses) has the greatest impact and is in the first place. The vertical trust (third hypothesis) is in the second place and institutional trust (first hypothesis) is in the third place. As a result, the last hypothesis in the fourth chapter showed that commitment to change had no strong impact on the relationship between organizational trust and organizational change so that it has only reduced 320 percent of the correlation between two variables.

According to the first main hypothesis, the significant positive relationship between organizational trust and organizational change in Sanandaj insurance companies was approved. The results of the study are in the same vein with the one conducted by Ben Gal and Tzafrir (2011). Based on the result of the main hypothesis, it is suggested:

The presence of conditions of trust keeps people together in the organizations and enables them to trust each other and to be open. Organizational trust makes employees feel secure and improves organizational performance and commitment and motivates employees to have performance beyond their duties.

According to the second sub-hypothesis, the significant positive relationship between horizontal trust and

${ }^{1}$ Root Mean Square Residual

${ }^{2}$ Goodness of Fit Index

${ }^{3}$ Non-Normed Fit Index 
organizational change in Sanandaj insurance companies was approved. The results of the study are in the same vein with the one conducted by Ben Gal and Tzafrir (2011). Based on the result of the main hypothesis, it is suggested:

To promote organizational trust, the company could use the help of consulting institutes' sensitivity training sessions. Sensitivity training is a technique to promote people social skills and abilities or it is a technique to improve communication between individuals. The purpose of this technique is to increase self-awareness, to grow personal character, to increase sensitivity, to learn how to evaluate their own and others' behavior, and to improve people awareness about their own and others' behavior patterns to which they themselves or other people may be allergic. Sensitivity training improves the employees' trust to each other as well as mutual trust between employees and managers.

According to the third sub-hypothesis, the significant positive relationship between vertical trust and institutional change in Sanandaj insurance companies was approved. The results of the study are in the same vein with the one conducted by Ben Gal and Tzafrir (2011). Based on the result of the main hypothesis, it is suggested:

Company managers should occasionally try to hold informal answer-question meetings between employees and managers; to inform the organization employees about the organization performance and goals in order to prevent any kind of workproblems; and to pay attention to employees' suggestions about the improvement of organizational methods and tasks. The organization can also use the suggestion system and consider rewards for employees offering the best suggestions for solving organizational problems or improving work methods.

According to the first sub-hypothesis, the significant positive relationship between institutional trust and organizational changes in Sanandaj insurance companies was approved. The results of the study are in the same vein with the one conducted by Ben Gal and Tzafrir (2011). Based on the result of the main hypothesis, it is suggested:

If the processes related to the production are of high quality, the employees' trust to the organization will increase. Such employees, due to their enjoyment of their workplace, are likely to take action which are beyond their duties but improve the organization and colleagues images.

According to the fourth sub-hypothesis, the significant positive correlation between organizational trust and commitment to change in Sanandaj insurance companies was approved. The results of the study are in the same vein with the one conducted by Ben Gal and Tzafrir (2011). Based on the result of the main hypothesis, it is suggested:

Encouraging commitment to implement changes in the employees directly is very difficult. Hence, to encourage these kinds of behavior in the organizational environments, its backgrounds should be recognized, strengthened, and managed. As it was researched in this study, change strategies and their dimensions have a positive impact on the commitment to implement the change. As a result, strengthening each of these aspects can strengthen commitment to implement the changes in the organization. Therefore, the organizations take actions to increase the level of the commitment to change through training and employment programs.

\section{Suggestions}

- Wages and bonus system should be carefully reviewed and the employees' amount of received pay should be consistent with the data delivered to the organization and with their effort.

- The organization manager should enhance his skilld in the management and ask for advice and guidance from those who are expert in this field and look at management as a science.

- Trust development requires that employees and managers are aware of each other's expectations and keep themselves responsible to establish an environment full of trust.

- Managers should rethink about their organizational structure and move towards decentralization and put their employees in the process of decision making and assigned to them the authority necessary to carry out these duties.

- Rewarding system should encourage a high level of trust and confidence in the organization through rewarding trustworthy behaviors and punishing discouraging behaviors.

- Development programs of occupational direction and performance evaluation system must be healthy and meaningful.

\section{Suggestions for Further Research}

- It is recommended that similar studies in other private organizations and other government agencies be carried out and the results be compared with these findings. 
- The quality of organizational trust can be compared between developed or developing countries in order to achieve sound management policies.

- Studying and determining the impacts of factors affecting institutional trust on decision-making and organizational policy-making

- Examining the problems related to the promotion and strengthening of organizational trust in Iranian organizations

\section{The Limitations of the Study}

- Unwillingness of some managers and officials to answer questions

- The extent and distribution of the research field which delayed collecting the questionnaires.

- Lack of research resources needed in Persian, especially in about the simultaneous relationship of three variables organizational trust, organizational change, and commitment to change, which takes a lot of time to collect materials and its translation and comparing the results with other results is limited.

\section{References}

Appelbaum, S. H. and Steed, A. J. (2005), "The critical success factors in the client-consulting relationship", Journal of Management Development, Vol. 24 Nos 1/2, pp. 68-93. http://dx.doi.org/10.1108/02621710510572362

Dirks K. T., Cummings L. L., pierce, J. L; "Psychological ownership in organizations: conditions under which individuals promote and resist change", Research in Organizational Change and Development, Vol. 9, 1996.

Hila Chalutz Ben-Gal, Shay S. Tzafrir. (2011). Emerald Article: Consultant-client relationship: one of the secrets to effective organizational change? Journal of Organizational Change Management.

Hooman, H.A. (2005). Understanding the scientific method in the behavioral sciences (research foundations). Tehran: Publication Parsa.

klein, K. J., \& Sorra, J. S. (1996); the Challenge of Innovation Implementation. Academy Of Management Review, 21, 1055-1080. http://dx.doi.org/10.5465/AMR.1996.9704071863

Kotter J., (1996) "Leading change"; Harvard Business School Press, Boston, MA.

Moghaddam, A., (2011). The role of mental models in the process of organizational change (Case study one of tissue paper producer in Iran). Expert Group to develop human resources

Pettigrew, A., (1990), "Longitudinal field research on change: theory and practice", Organization Science, Vol. 1 No. 3, pp. 267-92. http://dx.doi.org/10.1287/orsc.1.3.267

Pettigrew, A. M., Woodman, R. W. and Cameron, K. S. (2001), "Studying organizational change and development: challenges for future research", Academy of Management Journal, Vol. 44 No. 4, pp. 697-713. http://dx.doi.org/10.2307/3069411

Piderit, S. K. (2000). 'Rethinking resistance and recognizing ambivalence: A multidimensional view of attitudes toward an organizational change', Academy of Management Review, 25 (4): 783-794. http://dx.doi.org/10.5465/AMR.2000.3707722

Robert H. Guest, (1964): "organizational change: the effect of successful leadership", Dorsey press and Richard D. Irwin, Inc

Salavati, A., Salasi, P., (2014). The relationship between the "Strategies for Change" and "commitment to change". Volume 23, Issue 74, winter. Pages 47-71.

Singh A. Shoura M. M.; "A life cycle evaluation of change an engineering organization: A Case study"; International Journal of Project Management, Vol. 24, No. 337, 2006. http://dx.doi.org/10.1016/.ijproman.2005.11.001

Stanley, D. J., Meyer, J. P. and Topolnytsky, L. (2005), "Employee cynicism and resistance to organizational change", Journal of Business and Psychology, Vol. 19 No. 4, pp. 429-59. http://dx.doi.org/10.1007/s10869-005-4518-2

Szamosi, L. T. and Duxbury, L. (2002), "Development of a measure to assess organizationa

Weiss, H. M. and Cropanzano, R. (1996), "Affective events theory: a theoretical discussion of the structure, causes and consequences of affective experiences at work", Research in Organizational Behavior, Vol. 18, pp. 1-74.

Yarmohammadian, M.H., Shafipoormotlagh, F., Fooladvand, M. (2012). The relationship between organizational justice, job satisfaction and organizational trust and organizational commitment with the assessment of organizational excellence to provide a predictive model (case study in zone 4 of Islamic Azad university professor's of Iran). Quarterly Journal of New approach in educational management. Islamic Azad university. Fourth year. No. 1. pp. 18-1.

Zaheer, A., McEvily, B. and Perrone, V. (2003), "Does trust matter? Exploring the effects of inter-organizational and interpersonal trust on performance", Organizational Science, Vol. 9 No. 9, pp. 141-159. 